\title{
Mortality, Morbidity, Survival, and Burden of Top 9 Cancers in a Developing Country
}

\author{
Mohammad Khajedaluee ${ }^{1}$; Maliheh Dadgarmoghaddam ${ }^{1, *}$; Reza Saeedi ${ }^{1}$;Zahra Izadi-Mood ${ }^{2}$; \\ Maryam Abrishami ${ }^{1}$; Mina Zamani ${ }^{1}$ \\ ${ }^{1}$ School of Medicine, Mashhad University of Medical Sciences, Mashhad, IR Iran \\ ${ }^{2}$ Department of Statistics Experts in Health, Mashhad University of Medical Sciences, Mashhad, IR Iran \\ ${ }^{*}$ Corresponding author: Maliheh Dadgarmoghaddam, School of Medicine, Mashhad University of Medical Sciences, Mashhad, IR Iran. Tel: +98-9155084676, Fax: +98-5118002385, E- \\ mail: dadgarmm@mums.ac.ir
}

Received: May 7, 2014; Revised: May 28, 2014; Accepted: June 9, 2014

\begin{abstract}
Background: Cancer is one of the most important leading causes of morbidity and mortality worldwide.
Objectives: This study aimed to calculate the burden of 9 common cancers in the population covered by Mashhad University of Medical Sciences in Iran in 2010-2011.

Patients and Methods:We calculated disability adjusted life years (DALYs) for each of nine cancers according to the sex and age groups of (0-4, 5-14, 15-29, 30-44, 45-59, 60-69, 70-79, and $\geq 80$ years) using disease modeling (DisMod) version II software. The population-based data used in this study is mostly from cancer registries. The final estimates for the survival time were derived by combining several information sources. We applied $\mathrm{r}=0.03$ discounting and $\beta=0.04$ age weighting. In our study, the standard life expectancy considered 80 years for men and 82.5 for women.

Results: This study shows that the most years life lost (YLL) related to gastric, leukemia and lung cancers are 10116, 9564 and 7061 respectively. Cancers with the most years lost due to disability (YLD) were breast, brain and esophageal cancers (594, 506 and 460$)$. The most DALY related to gastric, leukemia and lung cancers (10516, 9803 and 722). The maximum DALY was for breast cancer (1550) seen in women aged $30-44$ years old.

Conclusions: It can be concluded that the YLL (93\%) has a major role in the burden of diseases in developing countries. Better strategies for improving the prevention and screening program are really needed in developing countries.
\end{abstract}

Keywords: Life Expectancy; Insurance, Disability; Developing Countries

\section{Background}

Non-communicable diseases (NCDs) are defined as diseases with long duration, generally slow progression and they are the major cause of adult mortality and morbidity worldwide (1). The four main NCDs are cardiovascular diseases, cancers, diabetes and chronic lung diseases. NCDs were responsible for two-thirds (36 million) of all deaths globally in 2011 (2). "Neoplasms are diseases characterized by abnormal proliferation of cells. If the proliferating cells invade surrounding tissues, the resultant tumor is malignant; if they do not, it is benign" (3). About $70 \%$ of all cancer deaths in 2008 occurred in low- and middle-income countries. Deaths from cancer worldwide are projected to continue rising, with an estimated 13.1 million deaths in 2030 (4). Cancer is the leading cause of death in developed and developing countries (5).

The burden of cancer is increasing in developing countries as a result of increased life expectancy and cancerassociated lifestyle choices including smoking, alcohol consumption, physical inactivity, and "westernized" diets (6). In developing countries poor access to cancer control and prevention lead to poorer survival rates.
In this study, we used disability-adjusted life years (DALYs) to measure loss of health as a result of illness in the population (7). DALYs represent a health gap; they measure the state of a population's health in comparison with normative goal which is to live in full health until standard life expectancy (8). DALYs, have two key components, Years Life Lost (YLL) related to premature mortality and Years Lost due to disability (YLD) (7). Without understanding the burden of cancer and prioritized based on it, implementation, monitoring and proper planning of interventions for prevention and control of cancer will not be possible.

\section{Objectives}

The main objective of this study was to assess the burden of cancer in the population covered by Mashhad University of Medical Sciences (total population: 5416163, male: 2748944, female: 2667219) in Iran in 2010-2011. Although the disease burden is calculated at a national level, but due to the high population in Khorasan Razavi province, the cancer burden was calculated separately for this province. 


\section{Patients and Methods}

DALYS for a disease are calculated as the sum of the year's life lost (YLL) and the years lost due to disability (YLD): DALY = YLL + YLD

The YLL is calculated as the number of deaths multiplied by the standard life expectancy at the age of death: $\mathrm{YLL}=\mathrm{N} \times \mathrm{L}$, which $\mathrm{N}$ and $\mathrm{L}$ represent: $\mathrm{N}$, number of deaths; $\mathrm{L}$, standard life expectancy at age of death in years.

Country-specific or model life tables with life expectancy data can be used to calculate YLLs. Most studies used the Coale and Demeny west level 26 and 25 life tables, developed by GBD (9). The west level 26 and 25 life tables are global model life tables that have a standard life expectancy at birth: 80.0 years for males and 82.5 years for females (10). In our study the standard life expectancy considered 80 years for men and 82.5 for women.

To estimate YLD, the number of incident cases is multiplied by the average duration of the disease and a weight factor that reflects the severity of the disease on a scale from 0 (perfect health) to 1 (dead). $\mathrm{YLD}=\mathrm{I} \times \mathrm{DW} \times \mathrm{L}$, which I, DW and L represent: I, number of incident cases; DW, disability weight; L, average duration of the case until remission or death (years). We used Dutch disability weights (DDW) in our study (11). DALYs presented in this study are age weighted $(\beta=0.04)$ and are discounted for time preference $(r=0.03)$. Age-weighting means that years lived at youngest and oldest age are given less weight and discounting means that future life years are assigned less value than now.

To calculate the cancer burden, we need to know the age and sex of target population, as well as the mortality data according to sex and age. In this study, the target population was the population under the coverage of Mashhad University of Medical Sciences.

The incident number of cancer cases and deaths according to sex and age were extracted from cancer registries and mortality statistics registration unit. The third index is selected Remission rate for cancers. The ratio of mortality (the number of deaths) to incidence (number of new cases), is also a proxy for 5-year survival. As an indirect measure of cancer survival, a mortality to incidence rate ratio (MR: IR) was calculated by dividing the mortality rate by the incidence rate; the higher the ratio, the lower the survival. Different societies have different quantities for this index. We wanted to use Weibull distribution in our study to calculate survival distribution but unfortunately, we obtained very limited information of cancer survivorship in the province and country and this information was limited to a few upper gastrointestinal tract cancers (esophagus and gastric) (12). Estimating the 5 years survival requires systematic assessment of the available evidence. The final estimates for the survival time were derived by combining several information sources, including cancer registries, seven peer-reviewed literatures (in developed and developing countries) and oncologist and hematologist medical claims. During panels and discussions, opinions of these experts were collected and used as a third index. We used disease modeling (DisMod) version II software for data analysis. These three factors and data from general population and general mortality data entered in to DisMod software and the output was used for calculating three indicators of disease burden YLD, YLL, DALY in association with software developed by the World Health Organization (YLD Templet, YLL Templet). We estimated DALYs for each cancer site by sex and age groups (0-4, 5-14, 15-29, 30-44, 45-59, $60-69,70-79$ and $\geq 80$ years)

\section{Results}

Table 1 show the disease burden of 9 common cancers

Table 1. Incidence Rate, YLL, YLD, DALY in 9 Common Cancers in the Population Under the Coverage of Mashhad Medical University $^{\mathrm{a}}$

\begin{tabular}{|c|c|c|c|c|}
\hline & $\begin{array}{c}\text { Incidence Rate Per } \\
1000000 \text { Population }\end{array}$ & YLL & YLD & DALY \\
\hline \multicolumn{5}{|l|}{ Gastric } \\
\hline Male & 20.44 & 6345 & 245 & 6590 \\
\hline Female & 7.16 & 3771 & 155 & 3926 \\
\hline \multicolumn{5}{|c|}{ Esophageal } \\
\hline Male & 11.42 & 1661 & 172 & 1833 \\
\hline Female & 9.29 & 1623 & 288 & 1911 \\
\hline \multicolumn{5}{|c|}{ Colorectal } \\
\hline Male & 10.11 & 1874 & 245 & 2119 \\
\hline Female & 7.42 & 835 & 154 & 989 \\
\hline \multicolumn{5}{|l|}{ Lung } \\
\hline Male & 5.45 & 4319 & 70 & 4389 \\
\hline Female & 3.33 & 2742 & 90 & 2832 \\
\hline \multicolumn{5}{|c|}{ Leukemia } \\
\hline Male & 8.33 & 5758 & 100 & 5858 \\
\hline Female & 6.67 & 3806 & 139 & 3945 \\
\hline \multicolumn{5}{|c|}{ Lymphoma } \\
\hline Male & 4.00 & 1630 & 53 & 1683 \\
\hline Female & 2.69 & 683 & 75 & 811 \\
\hline \multicolumn{5}{|l|}{ Brain } \\
\hline Male & 3.56 & 1836 & 169 & 2005 \\
\hline Female & 3.07 & 1559 & 337 & 1896 \\
\hline \multicolumn{5}{|l|}{ Breast } \\
\hline Male & - & - & - & - \\
\hline Female & 20.88 & 3014 & 594 & 3608 \\
\hline \multicolumn{5}{|l|}{ Prostate } \\
\hline Male & 9.53 & 1362 & 31 & 1393 \\
\hline Female & - & - & - & - \\
\hline \multicolumn{5}{|l|}{ Total } \\
\hline Male & 72.86 & 40195 & 1634 & 41829 \\
\hline Female & 60.54 & 29202 & 3476 & 32678 \\
\hline
\end{tabular}

a Abbreviations: DALY, disability adjusted life years; YLD, years lost due to disability; YLL, years life lost. 
in the population under the coverage of Mashhad Medical University in both sexes.

As seen in Table 1, the most common cancers were Gastric cancer in men (similar to developing countries pattern) and Breast cancer in women (similar to developed countries pattern), the total YLL, YLD, DALY were 69397, 5110 and 74507, respectively. So it can be concluded that YLL (93\%) has a major role in the burden of disease. In Figure $2 \mathrm{~A}-\mathrm{C}$, the number of years of life lost due to premature death from all cancers, the number of Years Lost due to Disability and disability adjusted life years due to all cancers in the population under the coverage by Mashhad Medical University is presented according to the age and sex. In our study, the maximum DALY from breast cancer (1550) was seen in women aged 30-44 years old. The maximum DALY from prostate cancer (545) was seen in men aged 70-79 years old.

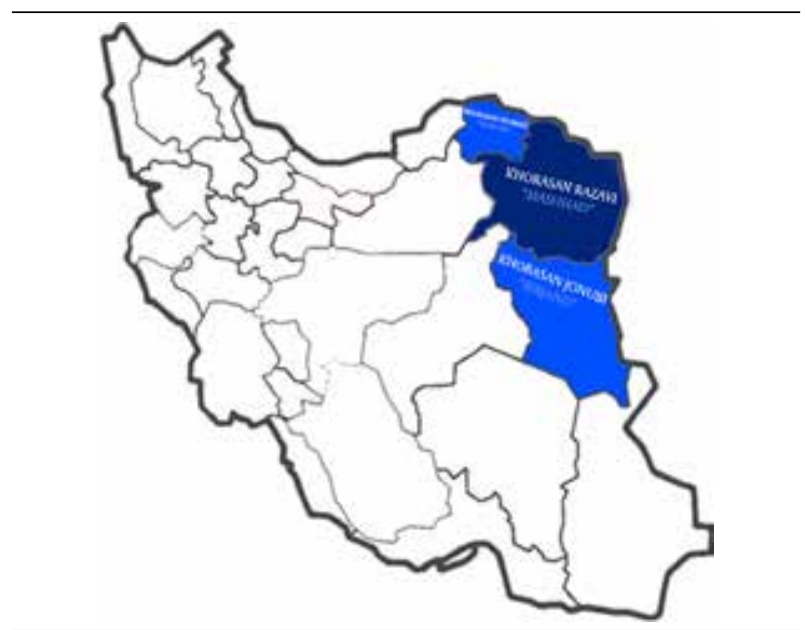

Figure 1. Geographical Map of Iran, Razavi Khorasan Province

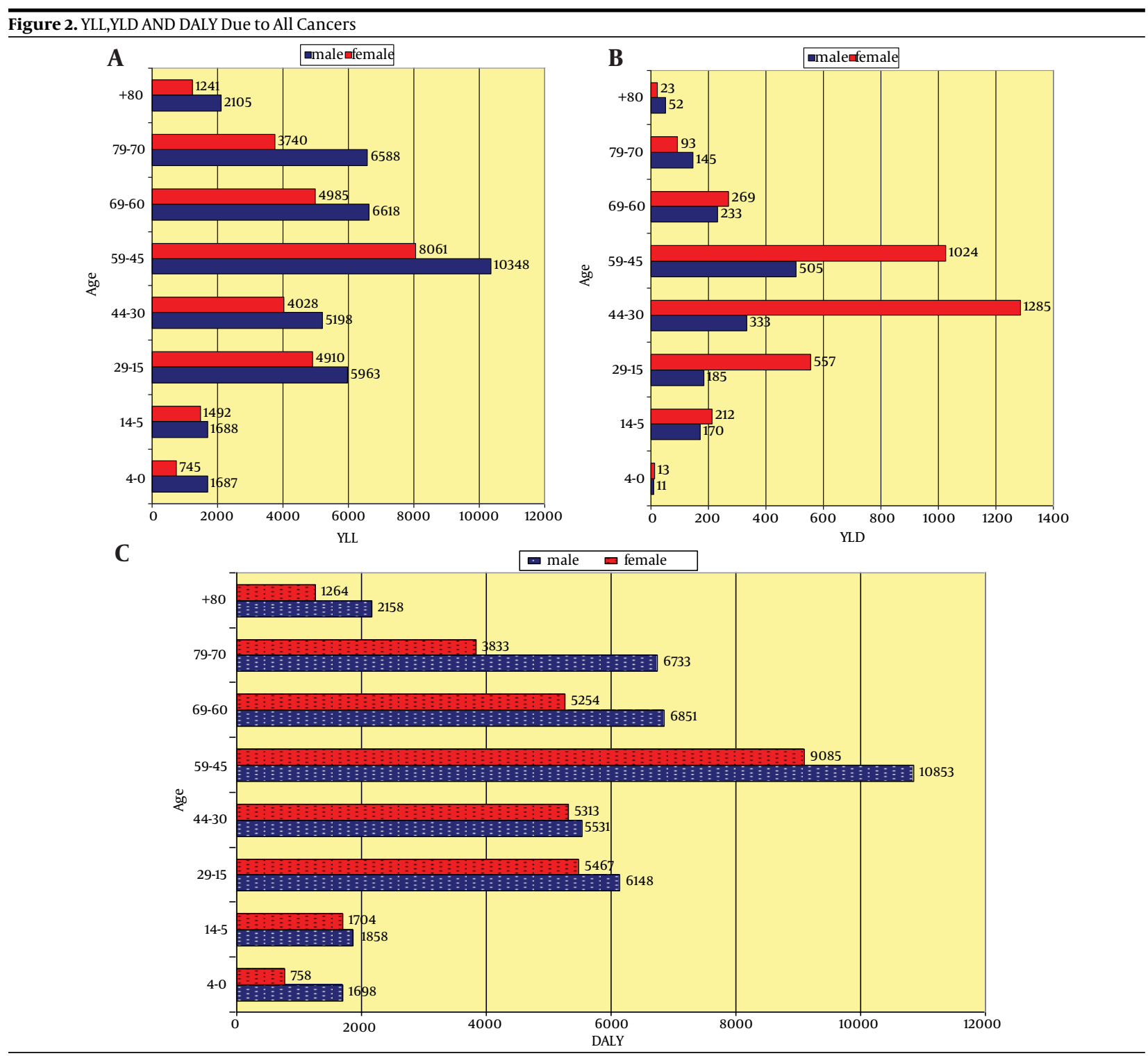

A) The number of years of life lost due to premature death from all cancers; B) The number of years lost due to disability and C) Disability adjusted life years due to all cancers in the population 


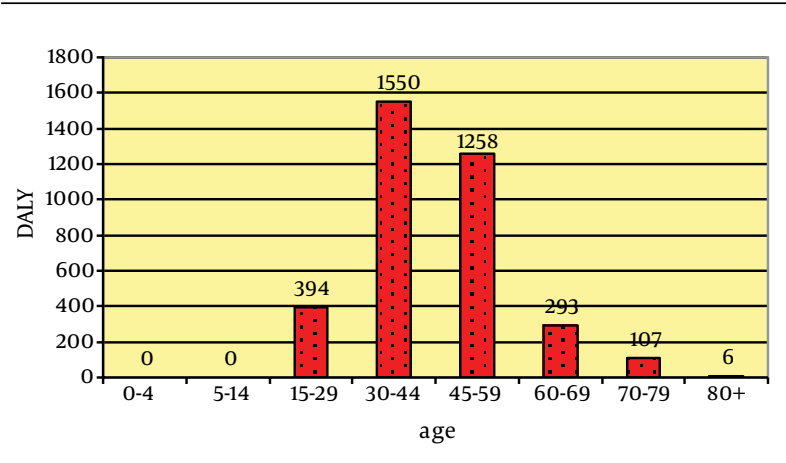

Figure 3. Disability Adjusted Life Years in Breast Cancer in Women

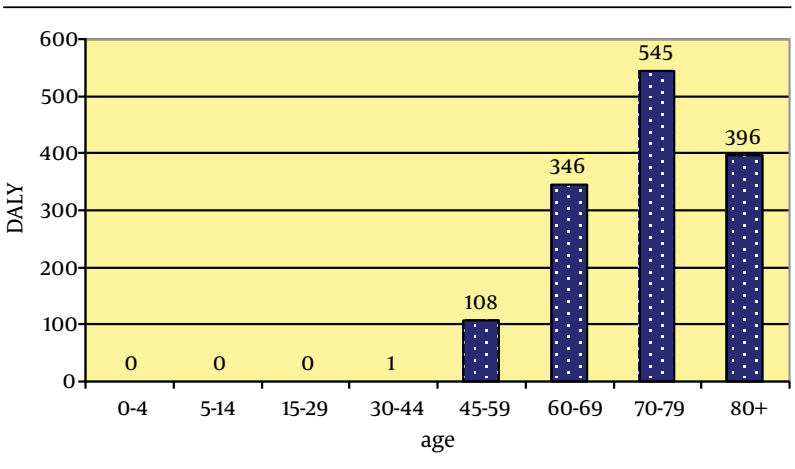

Figure 4. Disability Adjusted Life Years in Prostate Cancer in Men

\section{Discussion}

In our study the most YLL is related to gastric, leukemia and lung cancers (1016, 9564 and 7061), respectively. Cancers with the most YLD were breast, brain and esophageal cancers $(594,506$ and 460).The most DALY related to gastric, leukemia and lung cancers (10516, 9803 and 7221). The maximum DALY from breast cancer (1550) was seen in women aged 30-44 years old, because the breast cancer develops at lower age and is diagnosed at higher stage in Iran (13). We should bear in mind that in gastric cancer, $40 \%$ of years of life lost is due to premature death before age 60. So we can conclude that YLL has a major role in the burden of disease. YLL studied in seven cancers (gastric, esophageal, colorectal, lung, leukemia, lymphoma, brain) were higher in men than women.

Based on the previous study in Asia, the frequency of occurrence of different cancers is much different in Asia than in the United States (14). In the fifteen Asian countries, liver, esophageal, and stomach cancers predominate. In this study lung cancer has the highest incidence rate (age-standardized) of all cancers in males that is similar to developed countries, and breast cancer is the highest incident cancer for females. Lung cancer has the highest death rate (age-standardized) for males in the majority of these Asian countries, and breast cancer ranks among the top-five mortality rate cancers for females (14).

In a study, Lung, liver, breast, stomach, colorectal, cervi- cal, and esophageal cancers, and leukemia had the highest proportion of DALYs with a combined contribution of $65 \%$ to the total cancer burden (15), but in our country the incidence of liver cancer is very low. In Murray et al. study of 28 categories of cancer included in the analysis, four caused more than 15 million DALYs each: stomach cancer (0.7\%), other neoplasms (0.7\%), liver cancer $(0.8 \%)$, and trachea, bronchus, and lung cancers (1.3\%) (8).

Based on the results in our study and findings in other studies, YLLs were the most important component of DALYs in all world regions; however, it varied by region and cancer site. In one study in Australia, YLL contributed to $78 \%$ of the overall DALYs related to cancer in 2001 (16). In Soerjomataram et al. study mentioned that" lowresource settings had consistently higher YLLs than did high-resource settings" (17).

Some interventions have been done to reduce cancer incidence and mortality, and to prevent disability. Our data support the need for better attention to cancer prevention and treatment programs in developing countries. Our findings have shown that YLLs were the most important component of DALYs and have confirmed the poor prognosis after cancer diagnosis. High-quality treatment has not greatly improved survival for cancers with poor prognosis (e.g. lung, stomach, liver, pancreatic, and liver cancer); which emphasizes that primary prevention is the most important intervention to reduce the cancers burden. Our study had some strengths and limitations. Strengths of this study were In Iran:

I) Cancer registry system is accurate.

II) Cancer specific death rate is accurate.

III) Cause of death in cancers is accurate.

But limitations of this study were:

I) Survival in cancers was not specified.

II) We obtained very limited information of cancer survivorship in the province and country and this information was limited to a few upper gastrointestinal tract cancers (esophagus and gastric).

III) Cancer incidence data were available only for the 2010 and we must update and improve our cancer registry system.

Burden of disease studies provide valuable information that will assist in planning the future programs for population (18). Linking burden of disease studies to cost effectiveness analysis will facilitate priority setting in research and interventions.

The causes of cancer are diverse and complex. Researchers have estimated that as many as 2 in 3 cases of cancer (67 percent) are linked to some type of environmental factor, including use or abuse of tobacco, alcohol, food, exposures to radiation, infectious agents, and substances in the air, water, and soil (19) which these factors can directly damage genes (20). Approximately 5-10\% of cancers can be traced directly to inherited genetic defects (21). "Almost one-third of all cancer deaths could be prevented by not smoking, eating more vegetables, fruits and whole grains, eating less meat and refined carbohydrates, maintaining a healthy 
weight, exercising, minimizing sunlight exposure, and being vaccinated against some infectious diseases"(22).

So, we should pay attention to primordial, primary, secondary (early detection and screening), and tertiary prevention (treatment) programs to reduce the burden of cancers in all countries, and especially in developing countries. Health spending is not predominantly consumption.

\section{Acknowledgements}

With special thanks to Roham Salek, Fatemeh Homaee Shandiz, Amir Aldavood, Ghazale Shoja Razavi, Hamid Farhangi, Zahra Badiei, Maziar Moradi-Lakeh, Mohammad Reza joya, Gholam Hossein Khodaee, Ashraf Taghavi and Mohammad Hossein Ghoorchi. This study would not have been possible without their cooperation.

\section{Authors' Contributions}

Mohammad Khajedaluee: study concept and design, analysis and interpretation of data, final approval of the manuscript; Maliheh Dadgarmoghaddam: Interpretation of data, writing manuscript; Reza Saeedi: collecting of data, final approval of the manuscript; Zahra Izadi-Mood: collecting of data, final approval of the manuscript; Maryam Abrishami: collecting of data, final approval of the manuscript; Mina Zamani: collecting of data, final approval of the manuscript.

\section{Funding/Support}

This study was supported by Health Department in Mashhad University of Medical Sciences, Mashhad, Iran.

\section{References}

1. Abegunde D, Stanciole A. An estimation of the economic impact of chronic noncomunicable diseases in selected countries.Geneva: World Health Organization Department of Chronic Diseases and Health Promotion; 2006.

2. World Health Organization.. The top 10 causes of death. 2012. Available from: www.who.int/mediacentre/factsheets/fs310/en/ index2.html.

3. Wallace R. Public Health \& Preventive Medicine.USA: McGrawHill; 2008.

4. Bray F, Jemal A, Grey N, Ferlay J, Forman D. Global cancer transitions according to the Human Development Index (2008?2030): a population-based study. Lancet Oncol. 2012;13(8):790-801.

5. Ferlay J, Shin HR, Bray F, Forman D, Mathers C, Parkin DM. Estimates of worldwide burden of cancer in 2008: GLOBOCAN 2008. Int J Cancer. 2010;127(12):2893-917.
6. World Health Organization.. The GlobalBurden of Disease: 2004 Update. 2008. Available from: http://www.who.int/healthinfo/ global_burden_disease/GBD_report_2004update_full.pdf.

7. Murray CJL, Lopez AD. Global and regional descriptive epidemiology of disability: incidence, prevalence, health expectancies and years lived with disability. In: Murray CJL, Lopez AD editors. The Global Burden of Disease: A Comprehensive Assessment of Mortality and Disability from Diseases, Injuries, and Risk Factors in 1990 and Projected to 2020.. Boston, MA: Harvard University Press; 1996. pp. 201-46.

8. Murray CJ, Vos T, Lozano R, Naghavi M, Flaxman AD, Michaud C, et al. Disability-adjusted life years (DALYs) for 291 diseases and injuries in 21 regions, 1990-2010: a systematic analysis for the Global Burden of Disease Study 2010. Lancet. 2012;380(9859):2197-223.

9. Polinder S, Haagsma JA, Stein C, Havelaar AH. Systematic review of general burden of disease studies using disability-adjusted life years. Popul Health Metr. 2012;10(1):21.

10. Mathers CD, Vos T, Lopez AD, Salomon JA, Ezzati M. National Burden of Diseases Studies: A Practical Guide.Geneva: WHO Global Program on Evidence for Health Policy; 2001.

11. Melse JM, Essink-Bot ML, Kramers PG, Hoeymans N. A national burden of disease calculation: Dutch disability-adjusted life-years. Dutch Burden of Disease Group. Am J Public Health. 2000;90(8):1241-7.

12. Malekzadeh R, Derakhshan MH, Malekzadeh Z. Gastric cancer in Iran: epidemiology and risk factors. Arch Iran Med. 2009;12(6):576-83.

13. Mousavi SM, Montazeri A, Mohagheghi MA, Jarrahi AM, Harirchi I, Najafi M, et al. Breast cancer in Iran: an epidemiological review. Breast J. 2007;13(4):383-91.

14. McDonald MP, Hertz RW, Pitman S. The Burden of Cancer in Asia. 2008. Available from: www.pfizer.com/files/products/cancer_ in_asia.pdf.

15. Soerjomataram I, Lortet-Tieulent J, Ferlay J, Forman D, Mathers C, Parkin DM, et al. Estimating and validating disability-adjusted life years at the global level: a methodological framework for cancer. BMC Med Res Methodol. 2012;12:125.

16. Victorian burden of disease study: Mortality and morbidity in 2001.Melbourne: The Public Health Group, Rural and Regional Health and Aged Care Services Division; 2005.

17. Soerjomataram I, Lortet-Tieulent J, Parkin DM, Ferlay J, Mathers C, Forman D, et al. Global burden of cancer in 2008: a systematic analysis of disability-adjusted life-years in 12 world regions. Lancet. 2012;380(9856):1840-50.

18. Mathers CD, Vos ET, Stevenson CE, Begg SJ. The burden of disease and injury in Australia. Bull World Health Organ. 2001; 79(11):1076-84.

19. Anand P, Kunnumakkara AB, Sundaram C, Harikumar KB, Tharakan ST, Lai OS, et al. Cancer is a preventable disease that requires major lifestyle changes. Pharm Res. 2008;25(9):2097-116.

20. Kinzler KW, Vogelstein B. The genetic basis of human cancer.New York: McGraw-Hill, Medical Pub; 2002.

21. Bonta M, Bud C. Malignant Skin Tumors and Solar Radiations. Int JPharm Arch. 2014;3(1):273-84.

22. Kushi LH, Doyle C, McCullough M, Rock CL, Demark-Wahnefried W, Bandera EV, et al. American Cancer Society Guidelines on nutrition and physical activity for cancer prevention: reducing the risk of cancer with healthy food choices and physical activity. $C A$ Cancer J Clin. 2012;62(1):30-67. 